University of Montana

ScholarWorks at University of Montana

\title{
LAND COVER CHARACTERIZATION USING MULTITEMPORAL RED, NEAR-IR, AND THERMAL-IR DATA FROM NOAA/AVHRR
}

Ramakrishna R. Nemani

Steven W. Running

University of Montana - Missoula

Follow this and additional works at: https://scholarworks.umt.edu/ntsg_pubs Let us know how access to this document benefits you.

\section{Recommended Citation}

Nemani, R. and Running, S. (1997), LAND COVER CHARACTERIZATION USING MULTITEMPORAL RED, NEAR-IR, AND THERMAL-IR DATA FROM NOAA/AVHRR. Ecological Applications, 7: 79-90. doi:10.1890/ 1051-0761(1997)007[0079:LCCUMR]2.0.C0;2

This Article is brought to you for free and open access by the Numerical Terradynamic Simulation Group at ScholarWorks at University of Montana. It has been accepted for inclusion in Numerical Terradynamic Simulation Group Publications by an authorized administrator of ScholarWorks at University of Montana. For more information, please contact scholarworks@mso.umt.edu. 


\title{
LAND COVER CHARACTERIZATION USING MULTITEMPORAL RED, NEAR-IR, AND THERMAL-IR DATA FROM NOAA/AVHRR
}

\author{
Ramakrishna Nemani and Steve Running \\ School of Forestry, University of Montana, Missoula, Montana 59812 USA
}

\begin{abstract}
A simple land cover classification scheme is proposed based on energy absorption and exchange properties of various land cover types, observable from remote sensing. Seasonal trajectories of the Normalized Difference Vegetation Index (NDVI) and surface temperature $\left(T_{\mathrm{s}}\right)$, routinely available from NOAA/AVHRR (National Oceanic and Atmospheric Administration/Advanced Very High Resolution Radiometer), are used to characterize different land cover types into four groups: water limited (shrub, grass), energy limited (wetlands, boreal forests, snow, ice, and water), atmospherically coupled (aerodynamically rough canopies, forests), and atmospherically decoupled (aerodynamically smooth canopies, crops). Further separation is achieved using growing-season average NDVI for shrub and grass, seasonal NDVI amplitude for deciduous vs. evergreen, and nearinfrared (NIR) refiectance for broadleaf vs. needleleaf vegetation.

The methodology using threshold-based rules is completely remote sensing based; classification rules are simple and easily modifiable. A first test of this logic over the continental United States, when compared with existing maps, showed that the methodology adequately captures the spatial distribution of various land cover types. The logic is also useful for monitoring seasonal dynamics of land cover, evapotranspiration, and disturbances due to fire, floods, insects/disease, and other anthropogenic processes. Future improvements needed to deal with mixed landscapes and global implementation details are discussed.
\end{abstract}

Key words: canopy structure; land cover; remote sensing; surface temperature; vegetation index.

\section{INTRODUCTION}

Accurate parameterization of the structure and function of various land cover types is important for global carbon and climate models. Present global land cover maps have been derived using a wide variety of methodologies and data sources (Matthews 1983, Olson et al. 1983, Prentice et al. 1992). A detailed discussion on problems of these global land cover maps is found in Running et al. (1994a) and Townshend et al. (1991). The consensus from the above studies is that only remotely sensed data can provide accurate and repeatable means of global land cover classification and monitoring, in the advent of rapidly changing global land cover from anthropogenic processes. Consequently, providing reliable inventory of earth's land cover is one of the primary goals of NASA's (National Aeronautics and Space Administration) Earth Observing System (EOS) (Running et al. 1994b).

Remote sensing data have been used in a number of classification schemes at local, regional, and continental scales (Townshend et al. 1991). Many of these attempts were based on (1) similarity of reflected radi-

Manuscript received 14 November 1994; revised and accepted 10 January 1996; final version received 23 February 1996. For reprints of the Invited Feature, see footnote 1, p. 1. ation spectra of various land cover types in relation to specific training sites, or (2) temporal evolution of reflected radiation and its association to various phenological attributes of vegetation (Justice et al. 1985, Tucker et al. 1985, Loveland et al. 1991). Both approaches depend on statistical similarities to a predefined set of conditions based on observations or existing maps. But the generality of the predefined conditions is a cause for much confusion in classifications that requires enormous amounts of ancillary information to resolve (Loveland et al. 1991). Present classification schemes suffer from this ambiguity of what is needed vs. what is possible from remote sensing data alone (Running et al. 1994a).

Current continental to global scale classification schemes rely mostly on the magnitude and temporal evolution of spectral vegetation indices (SVI), i.e., combinations of RED and NIR reflectances such as NDVI (Justice et al. 1985, Tucker et al. 1985, Loveland et al. 1991). With a few exceptions, very little use has been made of the thermal infrared (TIR) observations collected simultaneously with those of RED and NIR (Achard and Blasco 1990). Recent studies have shown the potential of the combined analysis of spectral vegetation indices with surface temperature observations for studying surface energy exchange processes (Goward et al. 1985, 1994, Hope et al. 1986, Nemani and 


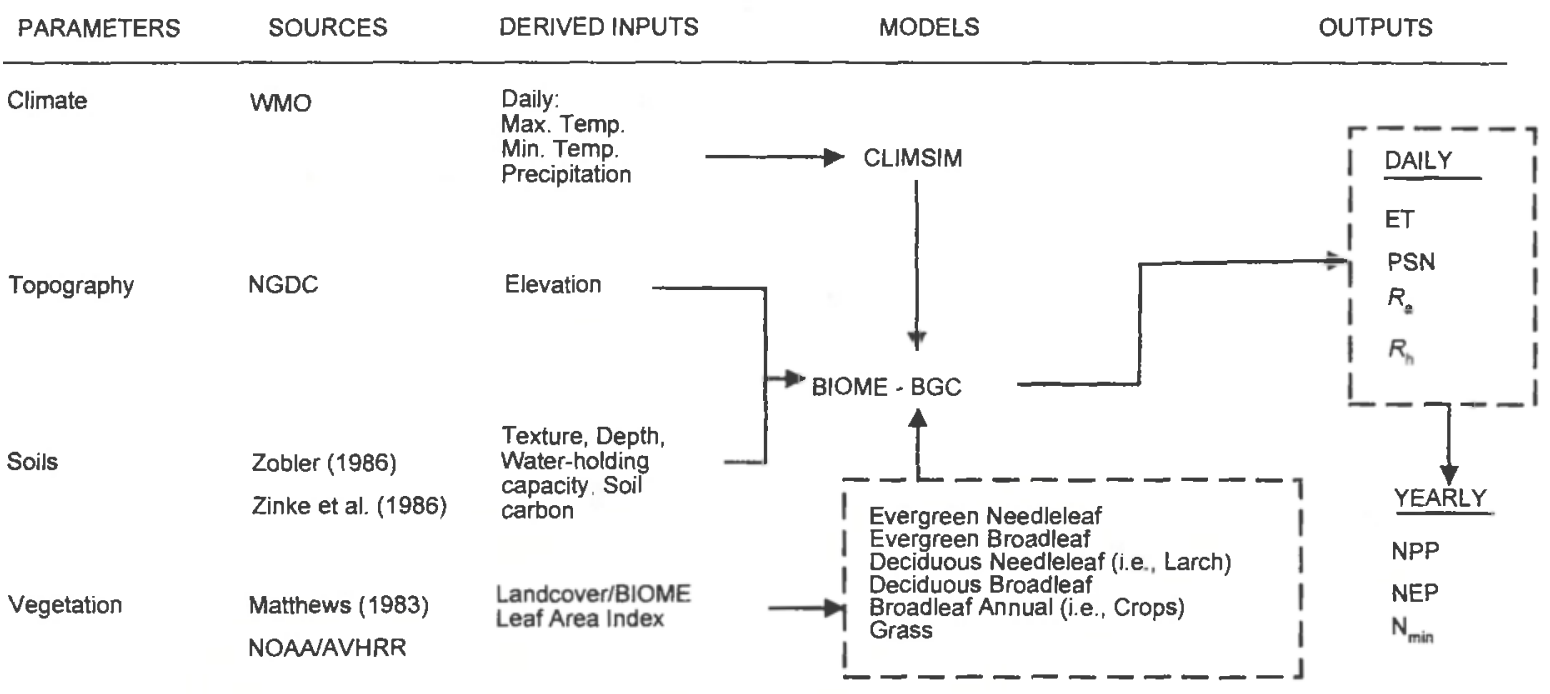

FiG. 1. Global Ecosystem Simulation System (GESSys): illustration of the integration of simulation models, CLIMSIM (Climate Simulation model) and BIOME-BGC (BioGeoChemical cycles) with climate, soils, and vegetation data to compute and map various carbon (PSN $=$ net photosynthesis, $\mathrm{kg} \mathrm{C} \cdot \mathrm{ha}^{-1} \cdot \mathrm{d}^{-1}$, NPP $=$ net primary production, $\mathrm{kg} \mathrm{C} \cdot \mathrm{ha}^{-1} \cdot \mathrm{d}^{-1}, \mathrm{NEP}=$ net ecosytem production, $\mathrm{kg} \mathrm{C} \cdot \mathrm{ha}^{-1} \cdot \mathrm{d}^{-1}, R_{\mathrm{a}}=$ autotrophic respiration, $\mathrm{kg} \mathrm{C} \cdot \mathrm{ha}^{-1} \mathrm{~d}^{-1}, R_{\mathrm{h}}=$ heterotrophic respiration, $\mathrm{kg}$ $\left.\mathrm{C} \cdot \mathrm{ha}^{-1} \cdot \mathrm{d}^{-1}\right)$, water $(\mathrm{ET}=$ evapotranspiration, $\mathrm{cm} / \mathrm{d})$, and nitrogen $\left(\mathrm{N}_{\min }=\right.$ nitrogen mineralization, $\left.\mathrm{kg} \mathrm{N} \cdot \mathrm{ha}^{-1} \cdot \mathrm{yr}^{-1}\right) \mathrm{fluxes}$.

Running 1989a, Price 1989, Carlson et al. 1990, Nemani et al. 1993). The combination of such multispectral data over time allows simultaneous observations of both radiation absorption and exchange properties, and may help in better surface characterization.

In this report, we present a new land cover classification method that uses multitemporal observations of Red, NIR, and surface temperature computed from TIR data. Our objective is to present a methodology in which the rules for classification are based on known energy exchange properties rather than statistical associations. The rules are designed to be simple and general enough to be implemented globally. Finally, the classification logic relies only on routinely collected satellite data and deals with both vegetation and nonvegetation. In this report, however, we concentrate our efforts on classification of global vegetation.

\section{TheOretical Basis for Classification

$$
\text { Ecology }
$$

Fig. 1 shows a schematic representation of information required on vegetation, soils and climate, data sources, and simulation models for computing and mapping global carbon, water, and nutrient flux processes. The primary ecosystem model, BIOME-BGC (Running and Hunt 1993), was designed to capture the essential physiomorphological adaptations that regulate energy exchange properties of vegetation. Running et al. (1994a) presented the ecological foundations for simplifying global vegetation into six classes, based on a combination of three primary attributes of plant canopy structure. Briefly these are (1) permanence of aboveground biomass: This attribute separates vegetation with permanent respiring biomass (forests and woody shrubs) from annual crops and grasses and is a major determinant of seasonal climate and carbon cycles. (2) Leaf longevity: The evergreen vs. deciduous nature of canopies is an extremely important variable for carbon and energy exchange processes through changes in albedo, carbon partitioning, and litterfall. (3) Leaf type or shape: This, i.e., broadleaf, needleleaf, and grass, is an important variable determining radiation absorption and gas-exchange characteristics. Combinations of these three attributes produce the six following classes: (1) evergreen needleleaf, (2) evergreen broadleaf, (3) deciduous needleleaf, (4) deciduous broadleaf, (5) broadleaf annual, and (6) grasses. Only broadleaf crops are identified separately. Since cereal crops behave similarly to grasses they were included in grasses.

This scheme differs from earlier classification efforts in the following ways. (1) Only plant attributes are used and climate is excluded from defining various classes. (2) It is tailored to the information content of remotely sensed observations. Though the number of classes will not meet all land-cover-related studies (changes in species composition due to changing climate etc.), it provides a stable and unambiguous starting point for further enhancements. This logic is also compatible with recent models of global vegetation distribution (Leemans and Cramer 1990, Prentice et al. 1992, Nielson 1994). We adopted this classification logic as the basis for our remote-sensing-derived implementation with minor modifications. We identified shrub as a special 


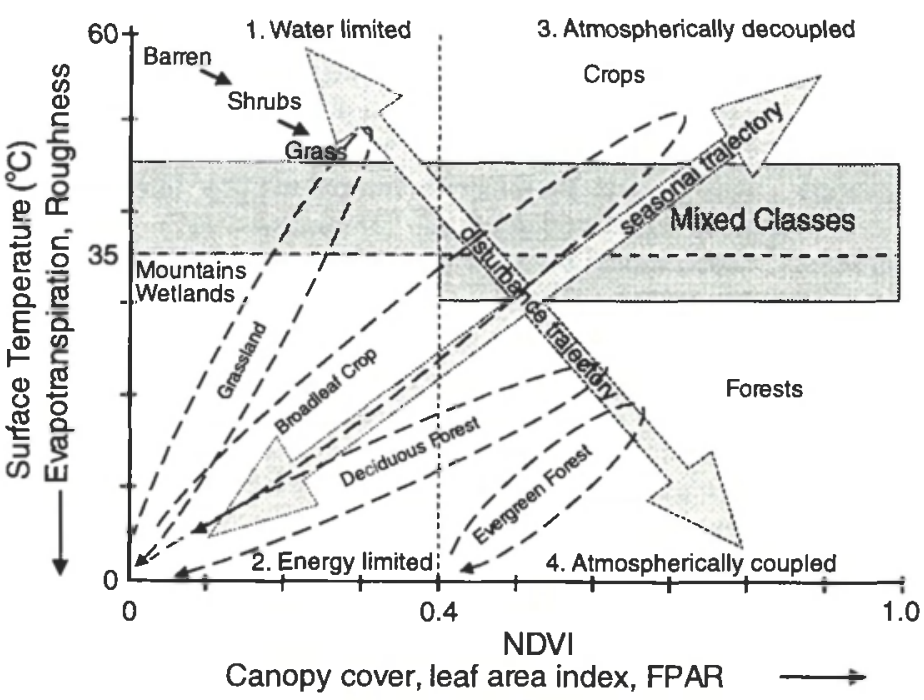

FIG. 2. Dynamics of $T_{\mathrm{s}}-\mathrm{NDVI}$ for various vegetation types, with a conceptual diagram showing the seasonal trajectories of different land cover types in the $T_{5}-$ NDVI space. The $T_{s}-$ NDVI space is divided into four simple groups with thresholds for NDVI $(0.4)$ and $T_{3}\left(35^{\circ} \mathrm{C}\right)$ chosen to represent energy absorption and exchange characteristics of various land cover types. While the seasonal trajectories indicate phenological evolution of vegetation, the disturbance trajectory is useful for change detection over time. Domains of mixed landscapes are identified as shaded areas. class that includes both broadleaf and needleleaf vegetation, but with small permanent biomass.

\section{Hydrometeorology and plant canopy structure}

Plant communities adapt and grow by optimizing use of resources such as water, nutrients, and solar radiation. The adaptations take various forms through changes in roughness (tall vs. short), leaf type (needleleaf vs. broadleaf), leaf longevity (deciduous vs. evergreen), and density (sparse vs. dense). These physiomorphological changes are fundamental mechanisms of optimizing the energy absorption and dissipation processes with water availability constraints (Woodward 1987). As water availability increases, plant canopy density increases. Increase in canopy density generally results in increase in plant height, therefore canopy roughness.

While plants growing in water-limiting conditions reduce the energy absorption with lower LAIs (Leaf Area Index) and canopy cover, plants with adequate water capture more energy but dissipate it efficiently to the atmosphere. The nature of coupling to the atmosphere has strong impact on the energy exchange processes of these canopies and the resulting canopy temperatures (Szeicz and Endrodi 1969, Jarvis and McNaughton 1986). Aerodynamically rough canopies such as forests dissipate energy efficiently and maintain canopy temperatures within $2^{\circ}-3^{\circ} \mathrm{C}$ of air temperatures (Denmead 1969). Similarly, needleleaf canopies have lower aerodynamic resistances, and therefore are strongly coupled to the atmosphere. Canopy temperatures in short, smooth canopies such as crops and grasses can be significantly higher than air temperatures (Denmead 1969). Therefore, changes in vegetation structure and function in response to resource availability should be useful for identifying various types of vegetation. If we can capture such differences in energy interactions through remote sensing, we will be able to classify vegetation based on fundamental principles rather than on statistical aggregations.

\section{Remote sensing}

Spectral vegetation indices and surface temperature observations from NOAA/AVHRR have been found to be useful for quantifying the energy absorption and exchange processes (Goward et al. 1994). Theoretical and experimental evidence suggests that SVIs are strongly related to the fraction of intercepted photosynthetically active radiation (FPAR), biomass, leaf area index, and canopy cover (Myneni et al. 1990, Baret and Guyot 1991, Asrar et al. 1992, Sellers et al. 1992, Goward et al. 1994). On the other hand, satellite-derived land surface temperatures are a function of energy exchange processes that are controlled by the fractions of soil and vegetation in the pixel, surface wetness, and synoptic weather conditions (Goward et al. 1985, Nemani et al. 1993). Differences in plant canopy structures produced as a result of climate and soil strongly influence the fractions of soil and vegetation in a pixel, and thus surface temperatures. Under dry surface conditions, surface temperatures are linearly related to canopy densities across different vegetation types (Nemani et al. 1993). Over wet surfaces the relation between $T_{\mathrm{s}}$ and canopy density is poorly defined (Nemani et al. 1993). However, the maximum-value compositing procedures followed in satellite data archives (Eidenshink 1992) tend to favor dry surface conditions (Nemani et al. 1993).

\section{Combined Classification Logic}

Fig. 2 illustrates idealized trajectories followed by various land cover types in the $T_{\mathrm{s}}-\mathrm{NDVI}$ space during a growing season. The $T_{\mathrm{s}}-\mathrm{NDVI}$ space is divided into four groups with thresholds for NDVI (0.4) and $T_{\mathrm{s}}(35)$, chosen to represent the relations between NDVI and FPAR, and reported surface temperatures for relatively 
closed canopies with adequate water supply (Gay 1972, Priestley and Taylor 1972, Sader 1986, Nemani and Running 1989a, Asrar et al. 1992, Goward et al. 1994). The theoretical basis for these thresholds will be discussed in detail later. We can characterize these groups in the following manner.

Group 1: water limited.-The hydrologic equilibrium theory states that plants regulate their leaf area index (i.e., energy absorption and exchange) in response to water availability determined by climate and soil properties (Woodward 1987, Nemani and Running $1989 b$, Nielson 1994). Plant communities such as grass and shrubs grow in drier climates or poor soil conditions with generally shorter growing seasons; they attain low density and shorter stature resulting in low canopy cover and energy absorption (low NDVI, thus low FPAR). Inadequate supply of water for evapotranspiration and plant growth and higher fractions of exposed soil also result in higher surface temperatures.

Group 2: energy limited.-Vegetation in high latitudes and altitudes generally has shorter growing seasons either due to low air temperatures or shorter day lengths, resulting in low levels of energy absorption. Boreal and alpine forests, snow- and ice-dominated landscapes, and open water and wetlands fall into this category. With adequate water for evapotranspiration these land cover types always have low Bowen ratios (the Bowen ratio is the ratio of sensible heat flux to latent heat flux and indicates how the energy absorbed at the earth's surface is dissipated, either in the form of evapotranspiration or as sensible heat) and low surface temperatures.

When energy and water conditions are nonlimiting for plant growth, energy dissipation processes become more important for distinguishing between land cover types. While albedo and canopy structure determine canopy net radiation, latent and sensible heat transfer are primary mechanisms for dissipating absorbed energy. The partitioning of energy is regulated by surface (stomatal control, leaf area index) and aerodynamic (roughness, windspeed) factors (Szeicz and Endrodi 1969).

Group 3: atmospherically decoupled.-Crops are a unique vegetation type, an exception to the ecological optimality, managed through irrigation and fertilization for harvesting solar energy. As a result crops have higher energy absorption (high NDVI). But crops also show higher surface temperatures for two reasons: (1) under low-to-moderate windspeeds crops are aerodynamically smooth compared to forests, therefore the high aerodynamic resistances suppress sensible heat transfer, resulting in higher $T_{\mathrm{s}}$ (Denmead 1969), (2) incomplete canopies through much of the growing season allow more radiation to penetrate and heat the underlying soil, thus contributing to higher surface temperatures.

Group 4: atmospherically coupled.-As climate/soil conditions become more favorable plant densities in- crease, leading to woodland/forest type vegetation with higher energy absorption (high NDVI and FPAR). Forests with their deep root systems tend to dissipate more energy by transpiration through much of the growing season, and therefore maintain canopy temperatures close to air temperatures (Denmead 1969). However, under adverse conditions they can also exert strong stomatal control on water losses (Jarvis and McNaughton 1986). Because forests are aerodynamically rough they can dissipate energy efficiently as sensible heat, and as a result maintain low $T_{\mathrm{s}}$. Further, forests generally have higher canopy covers and low fractions of exposed soils, again contributing to low radiometric temperatures.

\section{IMPLEMENTATION LOGIC}

Choice of the thresholds for NDVI and $T_{\mathrm{s}}$ is critical to the successful implementation of this logic. Theoretical as well as experimental evidence suggest that at an NDVI of 0.4 , many vegetation types absorb $>75 \%$ of incident photosynthetically active radiation (Myneni et al. 1990, Baret and Guyot 1991, Asrar et al. 1992). We understand that several factors, i.e., background, leaf optical properties, leaf angle distributions, and atmospheric conditions, strongly influence such a relation. Advances in sensor technology, better algorithms for atmospheric corrections, and proposed modifications for SVIs may allow a more robust choice for an NDVI threshold in the future (Huete et al. 1994, Running et al. 1994b).

Surface temperatures of well-watered closed canopies do not exceed $32^{\circ} \mathrm{C}$ under a wide range of net radiation conditions (Gay 1972, Priestley and Taylor 1972). The low Bowen ratios, in areas that support dense vegetation such as forests, help to maintain temperatures in equilibrium with energy availability. Further we assume that forest canopy temperatures (closed canopies with efficient energy dissipation) in spite of short-term water shortages do not exceed the $32^{\circ} \mathrm{C}$ limit by more than $2^{\circ}-3^{\circ} \mathrm{C}$ (Denmead 1969, Jarvis and McNaughton 1986, Luvall and Holbo 1991). Radiometric temperatures from satellite sensors are a complex function of viewing geometry and solar illumination along with other factors discussed earlier (Choudhury 1991). Nevertheless we chose to extend the theoretical temperature limits to pixel-wide surface temperatures.

Fig. 3 shows our classification scheme with the required variables and thresholds. Initial separation into four groups shown in Fig. 2 requires maximum values of NDVI, $T_{s}$, and a seasonal trajectory. The maximum values of NDVI and $T_{\mathrm{s}}$ that a pixel achieves during a growing season quickly establishes the nature of vegetation growing in the pixel (i.e., forests vs. nonforest etc.). The seasonal trajectory is used to alleviate the confusion caused by the maximum values, particularly in mixed landscapes. Using maximum values alone, a forest pixel with an NDVI of 0.5 and $T_{\mathrm{s}}$ value of $36^{\circ} \mathrm{C}$ 


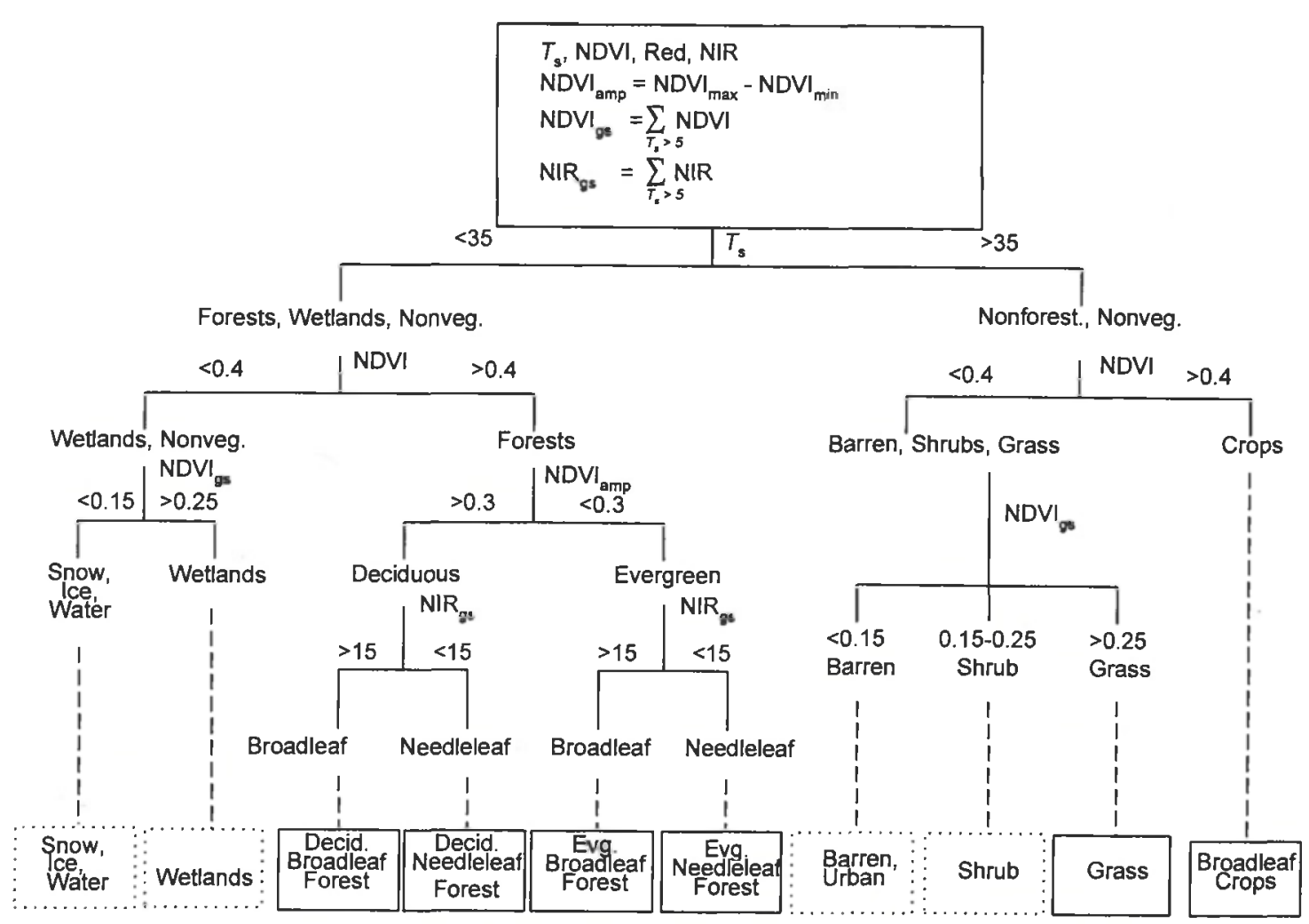

FIG. 3. Land cover classification from AVHRR data, with a flowchart of our classification logic showing the required variables and thresholds. Initial separation into the four simple groups is accomplished by the seasonal trajectory of $T_{s}-$ NDVI observations. The six vegetation classes defined in Running et al. (1994a) are shown in boxes with solid outlines. Climate is excluded from these definitions.

in only one composite period could be grouped with crops. The seasonal trajectories capture the differences in phenology, and growth rates between crops and forests produce distinct absorption/emission patterns. When temperatures become optimum for growth, broadleaf forests tend to leaf-out and achieve maximum canopy covers within a few weeks and maintain relatively low $T_{\mathrm{s}}$ (Schwartz and Karl 1990), whereas crops take longer time to achieve full canopy cover, and maintain higher $T_{\mathrm{s}}$ values for much of the growing season. Therefore, the length of time (in this case the number of composite periods) a pixel stays in a particular group other than group 1 (denoted as $T_{s} / \mathrm{NDVI}$ ) is also an important factor. Most vegetation types start their growth cycle in group 1 in temperate climates, whereas in the tropics it may be in group 1 or 2 (Fig. 2).

Further separation in each group is achieved using growing-season average NDVI (NDVI ${ }_{g s}$ ), growing-season average NIR reflectance $\left(\mathrm{NIR}_{\mathrm{gs}}\right)$, and growing-season NDVI amplitude ( $\mathrm{NDVI}_{\text {amp }}$ ). The definition of growing season is important for the onset of photosynthetic activity as well as for accurate analysis of satellite data. Because interpretation of satellite observations during the nongrowing season is complicated by low sun angles and snow cover, $\mathrm{NDVI}_{\text {amp }}, \mathrm{NIR}_{\mathrm{gs}}$, and $\mathrm{NDVI}_{\mathrm{ss}}$ are calculated for composite periods with $T_{\mathrm{s}}>5^{\circ} \mathrm{C}$, to represent a temperature-defined growing season.

\section{Water limited (group 1): barren, shrub, and grass}

It is very rare to see continuous canopies in shrubs and grass, because of the nature of climate and soil conditions on which they grow. Frequently, various fractions of grass, shrub, and bare soil are seen in natural landscapes. In a growing season, grasses tend to have higher canopy covers (although for shorter periods) than shrubs, resulting in slightly higher NDVI and higher FPAR. We used average growing-season NDVI $\left(\mathrm{NDVI}_{\mathrm{gs}}\right.$ ) to separate these three cover types (Fig. 3).

\section{Energy limited (group 2): snow, ice, water, and wetlands}

Landscapes dominated by snow, ice, and water usually stay within this group with NDVI values close to zero. Wetlands, on the other hand, have higher NDVI values because of the presence of vegetation. Boreal forests that have a significant fraction of surface water also fall in this group. We did not attempt further separation in this group for this study. We do plan to use satellite data collected as a part of the BOREAS (Boreal Ecosystem Atmosphere Study) experiment to further 
explore this group. Since group 3 (atmospherically decoupled) includes only broadleaf crops, no further separation is required.

\section{Atmospherically coupled (group 4): forests}

Since energy exchange properties of various forests are similar during a growing season, the reflectance dynamics and their magnitudes at different wavelengths are more important in further separation of forests into deciduous vs. evergreen and needle- vs. broadleaf forests.

Deciduous vs. evergreen.-Seasonal change in canopy cover is an important attribute for differentiating deciduous and evergreen vegetation. By definition evergreen vegetation-retains much of its canopy throughout the year, while deciduous canopies shed their leaves with canopy covers approaching zero. Such changes in canopy cover are captured by the seasonal NDVI profiles. However, extraneous factors such as snow cover and low illumination angles significantly reduce NDVI values that are not directly due to changes in canopy cover (Spanner et al. 1990). Presence of snow cover or low illumination angles also result in low surface temperatures. Therefore, a $T_{5}$-defined growing season significantly alleviates this problem. We chose an $\mathrm{NDVI}_{\text {amp }}$ of 0.3 to differentiate evergreen vs. deciduous canopies. We assumed an evergreen forest canopy with a maximum NDVI of 0.6 and maximum leaf turnover of $50 \%$ to arrive at an $\mathrm{NDVI}_{\text {amp }}$ threshold of 0.3 (Spanner et al. 1990, Loveland et al. 1991, Reed et al. 1994).

Needleleaf vs. broadleaf.-Canopies with broad leaves are spectrally brighter than those with needle leaves because of the canopy geometry and leaf angle distributions (Hall et al. 1992). For example, conifer canopies with spherical leaf angle distribution coupled with low specific leaf areas (leaf area per unit dry mass) tend to reflect very little radiation (Spanner et al. 1991). Though reflectances of individual needles are not significantly different from broad leaves, canopy reflectances were found to be quite smaller in needleleaf canopies. In contrast broadleaf vegetation with planophile canopies and higher specific leaf area tend to reflect more radiation. The differences in reflectance are particularly evident at near-infrared wavelengths (Hall et al. 1992). From satellite- and ground-based observations reported in various studies, we chose a cut-off of $20 \%$ average growing-season NIR reflectance to distinguish between needleleaf $(<20 \%)$ and broadleaf canopies $(>20 \%)$ (Hall et al. 1992).

\section{Methods}

\section{Data set}

We used 1-km NOAA/AVHRR data (channels 1-RED, 2-NIR, TIR-4, and TIR-5) collected and composited biweekly (once every 2 wk) during 1991 for the conterminous U.S. by the EROS Data Center. This data set is widely distributed and is similar to 1990 data set used for various land cover studies (Loveland et al. 1991, Eidenshink 1992). For each composite period, we computed NDVI as (NIR - RED)/(NIR + RED) and land surface brightness temperature as, $T_{\mathrm{s}}=$ $T_{\mathrm{s}} 4+3.3\left(T_{\mathrm{s}} 4-T_{\mathrm{s}} 5\right)$ (Price 1984), where $T_{\mathrm{s}} 4$ and $T_{\mathrm{s}} 5$ are brightness temperatures derived from TIR channels 4 and 5. The following attributes were created for a $2889 \times 4608$ pixel database: seasonal maximum values of $T_{\mathrm{s}}\left(T_{\mathrm{s} \max }\right)$ and NDVI (NDVI $\left.\mathrm{Imax}\right), T_{\mathrm{s}} / \mathrm{NDVI}, \mathrm{NDVI}_{\mathrm{amp}}$, $\mathrm{NDVI}_{\mathrm{gs}}$, and $\mathrm{NIR}_{\mathrm{gs}}$.

As the thresholds for this classification logic were not derived from training samples, we wanted to test the generality of our thresholds and assumptions. We chose a small sample of pixels to test the thresholds before applying the logic at continental scales.

\section{First test of the logic}

Using the Loveland et al. (1991) map, we chose 15, $2 \times 2$ pixel areas in each class, representing barren, brush, grass, broadleaf crops, conifer forests, and deciduous broadleaf forests in different climatic regimes (Fig. 4). A summary of important attributes used in our classification logic, obtained over different land cover classes, is given in Table 1.

\section{Continental application}

Each of the $2889 \times 4608$ pixels of the conterminous U.S. data was classified based on the logic shown in Fig. 3. The results from this approach were compared to the six classes reported in Running et al. (1994a), which were derived by merging Loveland et al.'s 73 classes. Since Loveland et al.'s (1991) original classification used an extensive amount of ancillary information and training data sets, we assumed this data set would provide a useful "ground truth" for our logic. We used every 50th pixel $(\approx 3000$, excluding water, snow, and ice) in the database for further comparative analysis (Table 2).

\section{REsults AND Discussion}

\section{First test of the logic}

The thresholds for NDVI (0.4) and $T_{\mathrm{s}}(35)$ appear to be adequate across the entire domain of the continental U.S. Mean values of $T_{\text {smax }}$ and NDVI $\mathrm{Imax}_{\max }$ for the test sites shown in Table 1 support our choice of these thresholds. A clear separation is observed from maximum values of NDVI and $T_{\mathrm{s}}$ between vegetation growing under energy or water-limiting (groups 1 and 2) and nonlimiting (groups 3 and 4) conditions (Table 1, Fig. 5a).

Seasonal trajectories of $T_{\mathrm{s}}$-NDVI ( $T_{s} / \mathrm{NDVI}$ ) contributed substantially to the group separation. The $T_{s} /$ NDVI alone could be used successfully to assign each pixel into one of the four groups (Fig. 5b). However, the variation between groups assigned by $T_{\text {smax }}$ and $\mathrm{NDVI}_{\text {max }}$ and by $T_{s} / \mathrm{NDVI}$ could provide valuable information about mixed landscapes. 


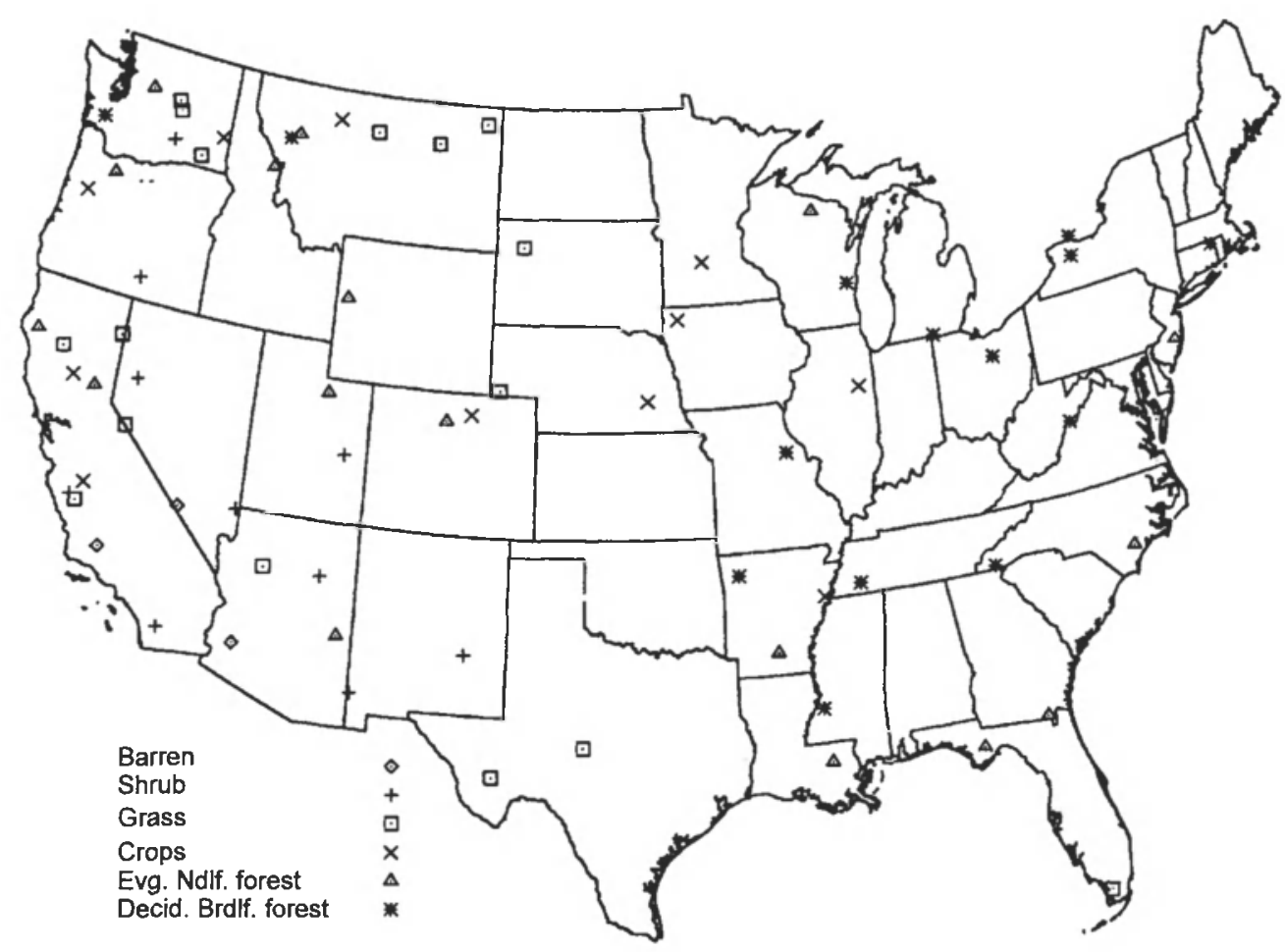

F1G. 4. Locations of sample sites for various land cover types across the continental U.S used in the initial testing of our classification logic.

Separating forests into deciduous and evergreen was reasonably accomplished through the NDVI amp threshold (Table 1). However, corrections for solar angle as well as eliminating snow periods through $T_{\mathrm{s}}$ values must be performed prior to computing $\mathrm{NDVI}_{\text {amp }}$ values. Some confusion still existed over high latitude forests where patchy snow and residual effects of sun-sensor geometry contributed to high $\mathrm{NDVI}_{\text {amp }}$ values over evergreen forests. On the average needleleaf canopies had 20-50\% lower NIR reflectance compared to broadleaf canopies, confirming earlier reports.
Maximum values alone could not clearly separate between crops and forests (Fig. 5a). Many pixels were found to fall in the mixed-canopy zone identified in Fig. 2. However, smoothed profiles of $T_{\mathrm{s}}$-NDVI (Fig. 5b) show that at a given NDVI crops have considerably higher $T_{\mathrm{s}}$ than forests, confirming the differences in canopy structure and energy exchange processes discussed earlier.

\section{Continental application}

The geographic distributions of various land cover types across continental U.S are well represented by

TABLE 1. Mean values of remotely sensed land surface characteristics used in the present classification system. $T_{s} /$ NDVI values represent the number of composite periods (total of 19 ) in which a pixel belonged to a group other than group 3 in Fig. 2.

\begin{tabular}{|c|c|c|c|c|c|c|c|c|c|c|c|}
\hline \multirow[b]{2}{*}{ Land cover } & \multirow{2}{*}{$\begin{array}{c}T_{s}^{\prime} \\
\text { NDVI }\end{array}$} & \multicolumn{2}{|c|}{$\mathrm{NDVI}_{\mathrm{gs}}$} & \multicolumn{2}{|c|}{$T_{s_{\text {max }}}$} & \multicolumn{2}{|c|}{$\mathrm{NDVI}_{\text {max }}$} & \multicolumn{2}{|c|}{$\mathrm{NDVI}_{\mathrm{amp}}$} & \multicolumn{2}{|c|}{$\mathrm{NIR}_{\mathrm{gs}}$} \\
\hline & & $\bar{X}$ & SD & $\bar{X}$ & SD & $\bar{X}$ & SD & $\overline{\bar{X}}$ & SD & $\bar{X}$ & SD \\
\hline Barren & 18 & 0.06 & 0.0 & 60 & 1 & 0.09 & 0.01 & 0.07 & 0.01 & 23 & 2 \\
\hline Shrub & 8 & 0.08 & 0.03 & 53 & 5 & 0.16 & 0.06 & 0.21 & 0.20 & 20 & 6 \\
\hline Grass & 9 & 0.20 & 0.03 & 48 & 5 & 0.35 & 0.05 & 0.27 & 0.04 & 18 & 3 \\
\hline Crops & 6 & 0.44 & 0.04 & 41 & 5 & 0.64 & 0.06 & 0.59 & 0.15 & 23 & 1 \\
\hline $\begin{array}{l}\text { Deciduous } \\
\text { broadleaf } \\
\text { forest }\end{array}$ & 10 & 0.44 & 0.04 & 32 & 3 & 0.62 & 0.05 & 0.50 & 0.07 & 26 & 2 \\
\hline $\begin{array}{l}\text { Evergreen } \\
\text { needleleaf } \\
\text { forest }\end{array}$ & 9 & 0.42 & 0.06 & 32 & 5 & 0.56 & 0.05 & 0.35 & 0.10 & 16 & 3 \\
\hline
\end{tabular}


TABLE 2. Comparison with Running et al. (1994a) classification. Numbers in parentheses are percentages of total pixels in each class.

\begin{tabular}{lcccccc}
\hline \hline & \multicolumn{7}{c}{ Our classification } \\
\cline { 2 - 7 } $\begin{array}{l}\text { Running et al. } \\
(1994 a)\end{array}$ & Barren & Shrub & Grass & Crops & Evg.ndl.for. & $\begin{array}{c}\text { Dec.bleaf. } \\
\text { for. }\end{array}$ \\
\hline Evg.ndl.for. & 0 & 0 & $41(5)$ & 6 & $676(77)$ & $148(17)$ \\
Shrub & 2 & $435(77)$ & $120(21)$ & 2 & 8 & 0 \\
Dec.bleaf.for. & 0 & 0 & 1 & 12 & $126(24)$ & $376(73)$ \\
Crops & 0 & 0 & $50(13)$ & $168(44)$ & $88(23)$ & $74(19)$ \\
Grass & 0 & $67(11)$ & $392(63)$ & $76(12)$ & $80(13)$ & 7 \\
Barren & $23(30)$ & $51(67)$ & 2 & 0 & 0 & 0 \\
\hline
\end{tabular}

Notes: Evg.ndl.for. = evergreen needleleaf forest, dec.bleaf.for. = deciduous broadleaf forest.
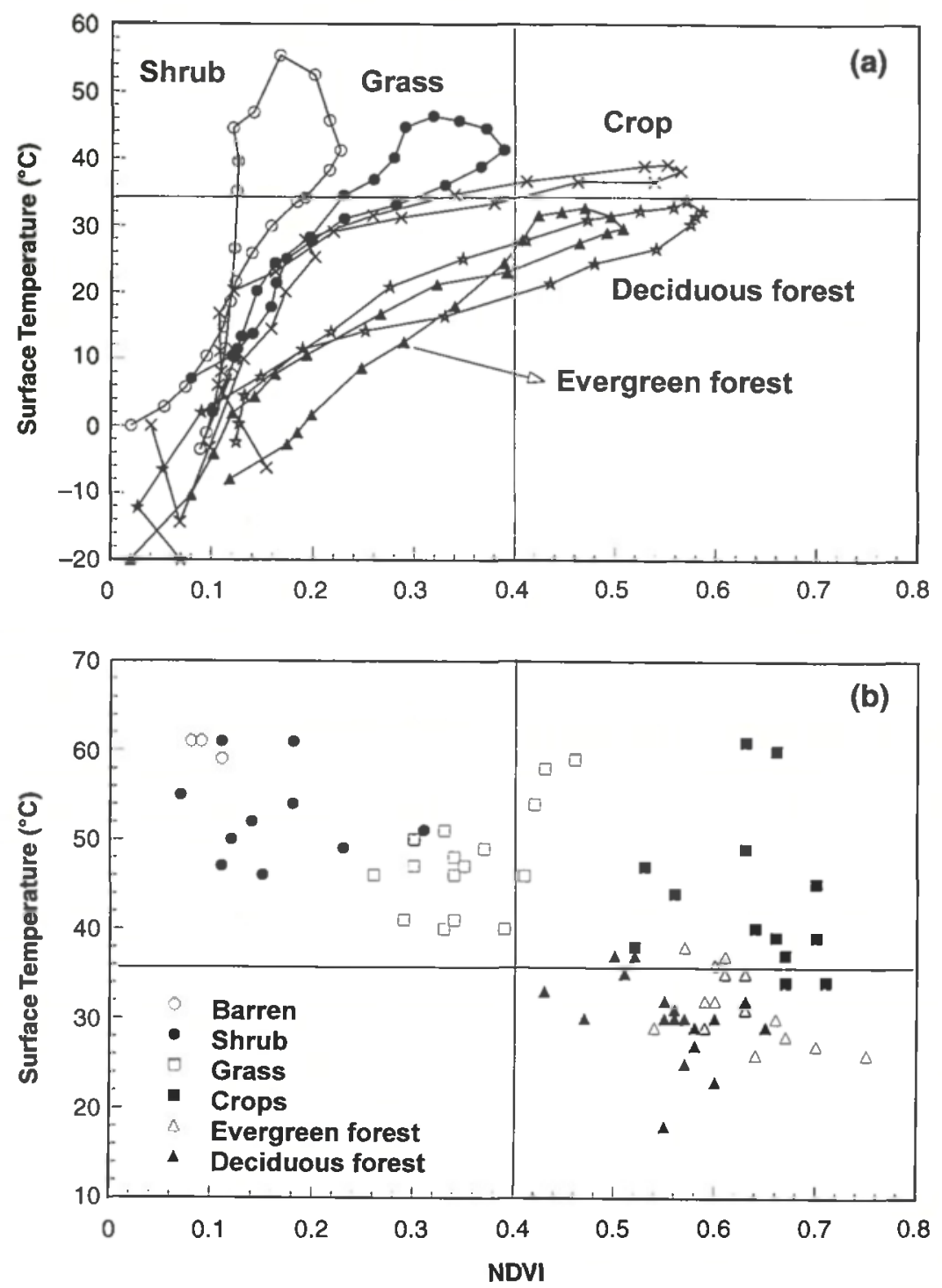

Fig. 5. (a) Seasonal trajectories for different land cover types in the $T_{i}$-NDVI space derived by smoothing raw NDVI and $T_{\mathrm{s}}$ data. Crops and forests around Lake Michigan, though sharing similar NDVI profiles, have remarkably different $T_{\mathrm{s}}$ responses, enhancing the discrimination capacity. Grass, shrub, and needleleaf forest examples are taken from Pacific Northwest region. (b) A $T_{\text {smax }}-\mathrm{NDVI}_{\max }$ scatterplot showing the distribution of pixels in different land cover classes from locations shown in Fig. 4. 


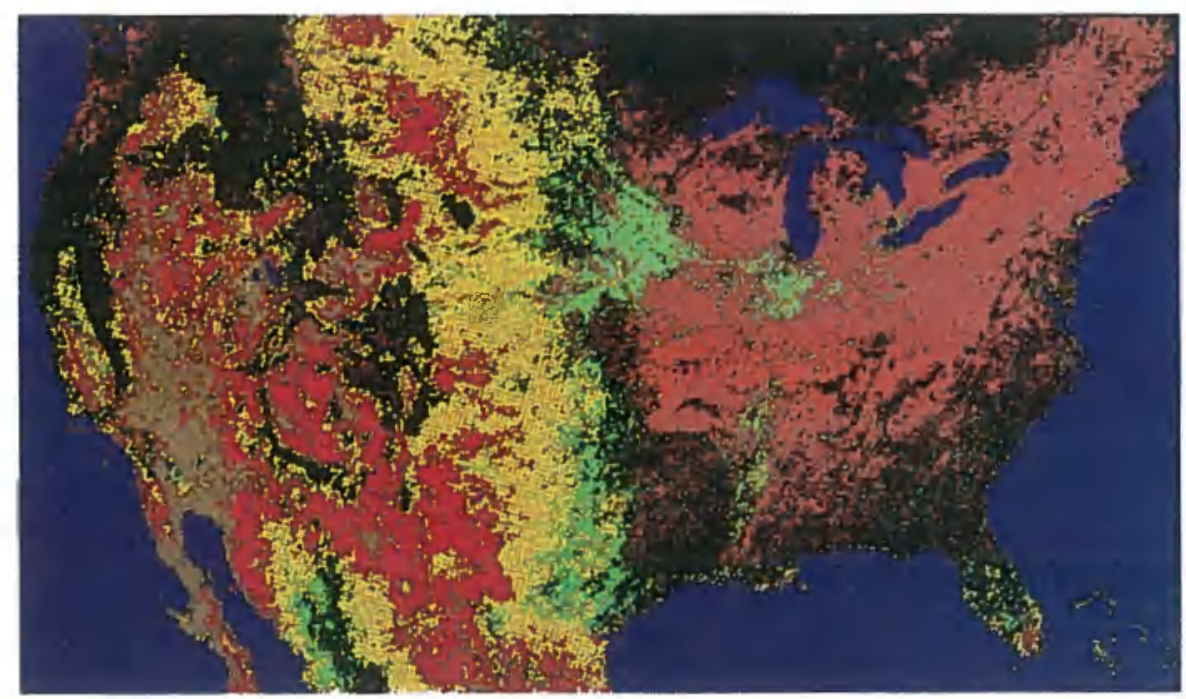

Water

Decid. Brdif. forest
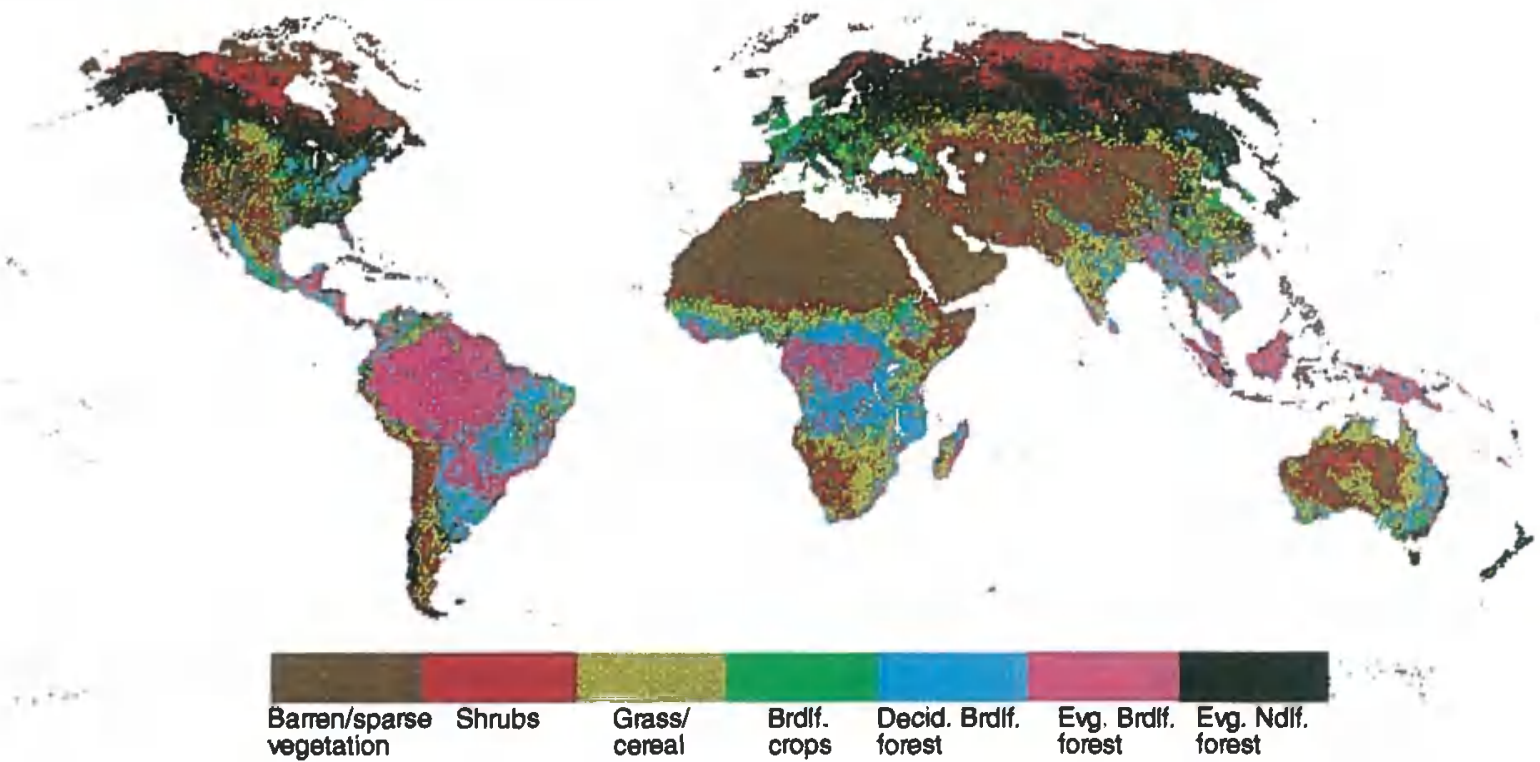

scale: $8 \times 8 \mathrm{~km}$

satellite data from NOANAVHRR, 1989

Plates 1-2. Plate 1 (top): A map showing various land cover classes for the conterminous U.S. derived using only remotely sensed data (RED, NIR, and TIR AVHRR data) and classification rules presented in Fig. 3. Plate 2 (bottom): Global land cover classes derived using the classification scheme presented in Fig. 3 with AVHRR/Pathfinder 8-km data for 1989.

our classification logic (Plate 1). Comparison of our results (Table 2) with those of Running et al. (1994a) showed $>90 \%$ accuracy in separating forests from nonforests. Accuracy decreased to 73 and $77 \%$, respectively, while separating evergreen needleleaf and deciduous broadleaf forests. However in both cases the remaining pixels ( 17 and $24 \%$ ) were assigned to a forest class only. Much of this confusion could be due to mixed landscapes such as those in the southern U.S., where various fractions of broadleaf and needleleaf for- ests co-exist. Examples of this are disturbed forests on the Oregon coast, in which broadleaf species (alder and aspen) dominate reflectance characteristics (Spanner et al. 1990). Our logic defined a number of pixels as deciduous broadleaf, whereas Running et al. (1994a) reported only needleleaf forests.

Shrubs were classified with an accuracy of $77 \%$, while $21 \%$ of the shrub pixels were assigned to grass. The barren class had similar problems, with more pixels assigned to shrub class. It is very difficult to argue 
what percentage of canopy cover differentiates shrubs from barren land and shrub from grass. There seems to be much overlap in $\mathrm{NDVI}_{\mathrm{gs}}$ values among these three land cover types due to variations in climatic and substrate conditions (Kremer and Running 1993). Open canopies with brighter substrates have been found to produce lower NDVI values compared to those with darker substrates (Asrar et al. 1992). Several new satellite indices have been proposed to account for such differences in background contribution (Huete et al. 1994).

Grass and crop classes have the lowest classification accuracies (Table 2). Landscape mosaics consisting of crops and grasses with forests are common over the continental U.S. Assigning such mixtures from Loveland et al. (1991) to one of the six classes (Running et al. 1994a) could be a difficult task and may be partly responsible for the poor agreement.

While several land cover maps exist for the U.S. (Matthews 1983, Olson et al. 1983, Wilson and Henderson-Sellers 1985, Defries and Townshend 1994) a quantitative comparison of our results with the above is a difficult task because of the differences in labelling the classes and coarse spatial resolution. Defries and Townshend (1994) clearly illustrate this problem of lack of correspondence among earlier maps by comparing the areal extents of various classes. A qualitative comparison of our results with earlier maps shows that major differences are usually in areas where cultivation has significantly altered the landscape. Currently no definitive data set of land cover exists against which results from various classification schemes can be tested (Defries and Townshend 1994). Several national as well as international efforts are currently underway to systematically collect land cover data over several test sites representing various land cover classes (Running et al. 1994b).

Land surface characterization can be significantly improved with the combined use of NDVI and surface temperatures. For example, irrigated crops and broadleaf forests in the eastern U.S. produce almost similar NDVI patterns, and yet the $T_{\mathrm{s}}$ profiles of these two surfaces would be different mainly because of the rate at which they achieve complete canopy closure. Consequently surface temperatures during the beginning and end of the growing season for crops are considerably higher compared to forests. Similarly high elevation forests in the Rocky mountains with departing snow cover and low elevation crops share similar NDVI profiles but remarkably different $T_{\mathrm{s}}$ profiles as a result of differential energy partitioning. Therefore, only a combined analysis of these two variables could capture the surface dynamics adequately.

In order to illustrate the robustness of the proposed algorithm, we used the AVHRR/Pathfinder data at 8-km resolution (James and Kalluri 1994) to map land cover at a global scale. Results of this analysis (Plate 2), though promising, demonstrated some key problems: (1) lack of mixtures like savana, (2) inability to identify deciduous needleleaf canopies. Currently, we are working on a number of improvements to the proposed method. Some of these are discussed below.

\section{Future improvements}

1. Thresholds for NDVI and $T_{s}$ - -Using a three-dimensional Radiative transfer model (Myneni et al. 1990), we are exploring the sensitivity of canopy reflectance to various structural and optical properties of vegetation. Such sensitivity analysis is likely to provide us with not only robust relations between canopy cover and NDVI, but also the possibility of using individual wavelength bands for detecting various types of vegetation. Thresholds for $T_{\mathrm{s}}$ are more difficult to generalize, as $T_{\mathrm{s}}$ is not an intrinsic property of vegetation itself. However, using the pathfinder data for the past 10-12 yr, we hope to derive geographically consistent thresholds for the surface temperature.

2. Mixed classes.-Mixed landscapes present problems mainly because of the spatial resolution of satellite data. The spatial resolution problem can only be solved with new satellite sensors such as MODIS (Moderate Resolution Imaging Spectroradiometer), MISR (Multi-angle Imaging Spectroradiometer), and ASTER (Advanced Spaceborne Thermal Emission and Reflection Radiometer) on board EOS (Earth Observing System) (Running et al. 1994b). Although the methodology presented here did not explicitly deal with mixed canopies, we identify the domains of mixed landscapes in the $T_{\mathrm{s}}$-NDVI space (Fig. 2). As discussed earlier, the discrepancy between groups assigned with $T_{\text {smax }}$ and $\mathrm{NDVI}_{\max }$ and with seasonal trajectory points to mixed landscapes (forests with grass/crops or grass with crops). In many western conifer forests open canopies with grass or brush understory are common. By midsummer the understory vegetation starts to senesce due to soil moisture deficits, thereby changing surface energy partitioning. The resulting increase in $T_{\mathrm{s}}$ may last only one or two composite periods before irradiance and air temperatures start falling. Similar responses in $T_{\mathrm{s}}$ can be expected with crop/forest mixtures. Also, appropriate modifications ( \pm ) to the $\mathrm{NDVI}_{\mathrm{gs}}$ and $\mathrm{NIR}_{\mathrm{gs}}$ thresholds would produce mixtures of deciduous vs. evergreen and needleleaf vs. broadleaf vegetation.

Finally, the performance of a classification algorithm is primarily determined by the quality of input data. Many of the current AVHRR data sets suffer from problems related to calibration, atmospheric influence, viewing geometry, and background effects. Planned algorithms for the EOS/MODIS products are designed to minimize the above effects, and would certainly help enhance the classification results (Running et al. 1994b).

\section{Conclusions}

We provided evidence that land surface temperatures when used in combination with spectral vegetation in- 
dices substantially improve land cover characterization. We realize the problems associated with satellitederived surface temperatures, including atmospheric and emissivity corrections and synoptic weather conditions. However, observed differences in surface temperatures between various land cover types are consistent, and are also useful for defining the onset of growing season, rate of plant growth, and aridity conditions. The logic combining NDVI and $T_{\mathrm{s}}$ is also useful for monitoring seasonal dynamics of land cover, evapotranspiration, and disturbances due to fire, floods, insects/disease, and other anthropogenic processes. The ecological foundations for simplifying global vegetation along with the completely remote-sensing-based implementation scheme should be a useful start for global land cover studies.

\section{ACKNOWLEDGMENTS}

Funding for this research was provided by NASA, grant NAGW-3151 and contract NAS5-31368.

\section{Literature Cited}

Achard, F., and F. Blasco. 1990. Analysis of vegetation seasonal evolution and mapping of forest cover in West Africa with the use of NOAA AVHRR HRPT data. Photogrammetric Engineering and Remote Sensing 56:1359-1365.

Asrar, G., R. B. Myneni, and B. J. Choudhury. 1992. Spatial heterogeneity in vegetation canopies and remote sensing of absorbed photosynthetically active radiation: a modeling study. Remote Sensing of Environment 41:85-101.

Baret, F, and G. Guyot. 1991. Potentials and limits of vegetation indices for LAI and APAR assessment. Remote Sensing of Environment 35:161-173.

Carlson, T. N., E. M. Perry, and T. J. Schmugge. 1990. Remote estimation of soil moisture availability and fractional vegetation cover over patchy vegetation. Agricultural and Forest Meteorology 52:44-60.

Choudhury, B. J. 1991. Multispectral satellite data in the context of land surface heat balance. Review of Geophysics 29:217-236.

Defries, R. S., and J. R. G. Townshend. 1994. NDVI-derived land cover classifications at a global scale. International Journal of Remote Sensing 15:3567-3586.

Denmead, O. T. 1969. Comparitive micrometeorology of a wheat field and a forest of Pinus radiata. Agricultural Meteorology 6:357-371.

Eidenshink, J. C. 1992. The 1990 conterminous U.S. AVHRR data set. Photogrammetric Engineering and Remote Sensing 58:809-813.

Gay, L. W. 1972. Radiative temperatures in the Willamette Valley. Northwest Science 46:332-335.

Goward, S. N., G. D. Cruickshanks, and A. S. Hope. 1985. Observed relation between thermal emission and reflected spectral radiance of a complex vegetated landscape. Remote Sensing of Environment 18:137-146.

Goward, S. N., R. H. Waring, D. G. Dye, and J. Yang. 1994. Ecological remote sensing at OTTER: satellite macroscale observations. Ecological Applications 4:322-343.

Hall, F. G., K. F. Huemmrich, D. E. Strebel, S. J. Goetz, J. E. Nickeson, and K. D. Woods. 1992. Biophysical, morphological, canopy optical property, and productivity data from the superior National Forest. NASA Technical Memorandum 104568.

Hope, A. S., D. E. Petzold, S. N. Goward, and R. M. Ragan. 1986. Simulated relationships between spectral reflectance, thermal emissions and evapotranspiration of a soybean canopy. Water Resources Bulletin 22:1011-1019.

Huete, A., C. Justice, and H. Liu. 1994. Development of vegetation and soil indices for MODIS-EOS. Remote Sensing of Environment 49:224-234.

James, M. E., and S. N. V. Kalluri. 1994. The Pathfinder AVHRR land data set: an improved coarse resolution data set for terrestrial monitoring. International Journal of Remote Sensing 15:3347-3364.

Jarvis, P. G., and K. G. McNaughton. 1986. Stomatal control of transpiration: scaling up from leaf to region. Advances in Ecological Research 15:1-49.

Justice, C. O., J. R. G. Townshend, B. N. Holben, and C. J. Tucker. 1985. Analysis of the phenology of global vegetation using meteorological satellite data. International Journal of Remote Sensing 6:1271-1381.

Kremer, R. G., and S. W. Running. 1993. Community type differentiation using NOAA/AVHRR data within a sagebrush-steppe ecosystem. Remote Sensing of Environment 46:311-318.

Leemans, R., and W. Cramer. 1990. The IIISA climate data base for land areas on a grid with 0.5 degree resolution, WP-90-41, International Institute for Applied Systems Analysis, Laxenburg, Austria.

Loveland, T. R., J. W. Merchant, D. O. Ohlen, and J. F. Brown. 1991. Development of a land-cover characteristics database for the conterminous U.S. Photogrammatic Engineering and Remote Sensing 57:1453-1463.

Luvall, J. C., and H. R. Holbo. 1991. Thermal remote sensing methods in landscape ecology. Pages 127-152 in M. G. Turner and R. H. Gardner, editors. Quantitative methods in landscape ecology. Springer-Verlag, New York, New York, USA.

Matthews, E. 1983. Global vegetation and land use: new high-resolution data bases for climate studies. Journal of Climate and Applied Meteorology 22:474-487.

Myneni, R., G. Asrar, and S. A. W. Gerstl. 1990. Radiative transfer in three dimensional leaf canopies. Transport Theory and Statistical Physics 19:1-54.

Nemani, R. R., and S. W. Running. 1989a. Estimation of surface resistance to evapotranspiration from NDVI and Thermal-IR AVHRR data. Journal of Applied Meteorology 28:276-284.

Nemani, R., and S. W. Running. 1989b. Testing a theoretical climate-soil-leaf area hydrologic equilibrium of forests using satellite data and ecosystem simulation. Agricultural and Forest Meteorology 44:245-260.

Nemani, R., L. L. Pierce, S. W. Running, and S. N. Goward. 1993. Developing satellite derived estimates of surface moisture status. Journal of Applied Meteorology 32:548557.

Nielson, R. P. 1994. A model for predicting continental scale vegetation distribution and water balance. Ecological Ap. plications 5:362-385.

Olson, J. S., J. A. Watts, and L. J. Allison. 1983. Carbon in live vegetation of major world ecosystems (TR004). U.S. Department of Energy, Washington, D.C., USA.

Prentice, C., W. Cramer, S. Harrison, R. Leemans, R. Monserud, and R. Solomon. 1992. A global biome model based on plant physiology and dominance, soil properties and climate. Journal of Biogeography 19:117-134.

Price, J. C. 1984. Land surface measurements from the split window channels of NOAA-7 AVHRR. Journal of Geophysical Research 89:7231-7237.

- 1989. Using the spatial context in satellite data to infer regional scale evapotranspiration. IEEE (Institute of Electrical and Electronic Engineers) Transactions of Geoscience and Remote Sensing 28:940-948.

Priestley, C. H. B., and R. J. Taylor. 1972. On the assessment 
of surface heat flux and evaporation using large-scale parameters. Monthly Weather Review 100:81-92.

Reed, B. C., J. F. Brown, D. VanderZee, T. R. Loveland, J. W. Merchant, and D. O. Ohlen. 1994. Measuring phenological variability from satellite imagery. Journal of Vegetation Science 5:703-714.

Running, S. W., and E. R. Hunt. 1993. Generalization of a forest ecosystem process model for other biomes, BIOMEBGC, and an application for global-scale models. Pages 141-158 in J. Ehleringer and C. Field, editors. Scaling physiological processes: leaf to globe. Academic Press, London, England.

Running, S. W., T. Loveland, and L. L. Pierce. 1994a. A vegetation classification logic based on remote sensing for use in global biogeochemical models. Ambio 23:77-81.

Running, S. W., C. O. Justice, V. Salomonson, D. Hall, J. Barker, Y. J. Kaufmann, A. H. Strahler, A. R. Huete, J-P. Muller, V. Vanderbilt, Z. M. Wan, P. Teillet, and D. Carneggie. $1994 b$. Terrestrial remote sensing science and algorithms planned for EOS/MODIS. International Journal of Remote Sensing 15:3587-3620.

Sader, S. A. 1986. Analysis of effective radiant temperatures in a Pacific Northwest forest using thermal infrared multispectral scanner data. Remote Sensing of Environment 19: 105-115.

Schwartz, M. D., and T. Karl. 1990. Spring phenology: nature's experiment to detect the effect of "green up" on surface maximum temperatures. Monthly Weather Review 118:883-890.
Sellers, P. J., J. A. Berry, G. J. Collatz, C. B. Field, and F. G. Hall. 1992. Canopy reflectance, photosynthesis and transpiration. III. A reanalysis using improved leaf models and new canopy integration scheme. Remote Sensing of Environment 42:187-216.

Spanner, M. A., L. L. Pierce, S. W. Running, and D. L. Peterson. 1990. The seasonality of AVHRR data of temperate coniferous forests: relation to leaf area index. Remote Sensing of Environment 33:97-112.

Szeicz, G., and G. Endrodi. 1969. Aerodynamic and surface factors in evaporation. Water Resources Res. 5:380-394.

Townshend, J. R. G., C. O. Justice, W. Li, C. Gurney, and J. McManus. 1991. Global land cover classification by remote sensing: present capabilities and future possibilities. Remote Sensing of Environment 35:243-255.

Tucker, C. J., J. R. G. Townshend, and T. E. Goff. 1985. African Landcover classification using satellite data. Science 227:369-375.

Wilson, M. F, and A. Henderson-Sellers. 1995. A global archive of land cover and soils data for use in general circulation models. Journal of Climatology 5:119-143.

Woodward, F. I. 1987. Climate and plant distribution. Cambridge University Press, Cambridge, UK.

Zinke, P. J., A. G. Stangenberger, W. M. Post, and J. S. Olson. 1986. Worldwide organic soil carbon and nitrogen data. ORNL/TM-8857. Oak Ridge National Laboratory, Oak Ridge, Tennessee, USA.

Zobler, L. 1986. A world soil file for global climate modeling. NASA Technical Memorandum 87802. 